\title{
Tethering Natural Capital and Cultural Capital for a More Sustainable Post-COVID-19 World
}

\author{
Craig A Talmage ${ }^{1}$ D $\cdot$ Beth Allgood $^{2}$ Brien K. Ashdown ${ }^{3} \cdot$ Ava Brennan $^{1}$. \\ Sally Hill ${ }^{4}$ Eric Trevan ${ }^{5}$. John Waugh ${ }^{6}$
}

Received: 15 December 2020 / Accepted: 1 November 2021 / Published online: 7 January 2022

(c) The Author(s), under exclusive licence to Springer Nature Switzerland AG 2021

\begin{abstract}
The world faced stark challenges during the global pandemic caused by COVID-19. Large forces such as climate change, cultural ethnocentrism and racism, and increasing wealth inequality continue to ripple through communities harming community well-being. While the global pandemic caused by COVID-19 exacerbated these forces, lessons across the globe have been captured that inform the field of community well-being long-after the end of the pandemic. While many scholars have looked to political capital, financial capital, and social capital to tackle these challenges, natural capital and cultural capital have extreme relevance. However, scholarship tends to overlook the inextricable and important links between natural capital and cultural capital in community development and well-being work. These capital forms also inform contemporary understandings of sustainability and environmental justice, especially in the fields of community development and well-being. This perspective article showcases the deep connections between natural capital and social capital through literature review and community cases across the globe. Questions are posed for future research and practice tethering together cultural capital and natural capital when looking to bolster community well-being.
\end{abstract}

Keywords Community development $\cdot$ Sustainable community development . Community capitals $\cdot$ Sustainable livelihoods $\cdot$ Community well-being $\cdot$ Community capitals

\section{Background and Purpose}

Many citizens of the world are keenly aware of the intersecting forces that threaten social, economic, and ecological systems, including: (1) climate change; (2) novel coronaviruses; (3) racism and cultural ethnocentrism; and, (4) rising wealth

Craig A Talmage

Talmage@hws.edu

Extended author information available on the last page of the article 
inequality. These forces ripple across the globe, and many communities fear global economic collapse and widespread unrest (e.g., Lee, 2020a). Recognizing these forces and the global stakes, communities must shift strategies to maintain community health and well-being. Locally and globally, communities are searching for responses to these forces to ensure health and well-being for all, today and for generations to come (e.g., Munro et al., 2020).

This article enhances community development (CD) theory and practice by tethering together contemporary understandings of natural capital and cultural capital to inform practices to bolster community well-being, during the COVID-19 pandemic and beyond. The article attempts to better infuse economic, environmental, and social justice in both scholarship and practice to enhance CD and respond to the ways the COVID-19 pandemic is changing the world. Examples of the forces noted above and their impacts are leveraged to generate insights, and questions are offered to further develop theory and enlighten practice.

\section{Contemporary CD Approaches: Sustainable Livelihoods and Community Capitals}

$\mathrm{CD}$ and sustainability have co-mingled in scholarship and practice for years. CD can encompass practices, processes, programs, outcomes, and ideologies (Phillips $\&$ Pittman, 2009). Such conceptualizations are focused not only on common destinations and locations, but also common sets of ideas and values (Trevan, 2016; Phillips \& Pittman, 2009). Bhattacharyya's (2004) conceptualizes community as solidarity and development as agency, but where do sustainability or sustainable community development (SCD) fit?

Dale and Newman (2010) have posited SCD as a reconciliatory process, where communities must balance themselves between two positions: (1) do we aim to get by or (2) do we aim to get ahead? Sustainability thus adds long-term commitments and accountability to properly steward community resources as well as provide equitable access to those resources. Still, the discipline of CD has some struggles and problems; simply adding the $\mathrm{S}$ to $\mathrm{CD}$ does not absolve the field of the problems in $\mathrm{CD}$ work. CD is not without its dark sides, including corrupted processes or (unintended) harmful outcomes. CD scholars and practitioners should consider bad intentions, power, and harm in their work (Talmage \& Gassert, 2020) and must ask if SCD efforts are sustainable for all or for whom?

Interdisciplinary attempts to define SCD have emerged across the fields of business, economic development, rural development, youth development, ecology, environmental studies, natural resource management, nonprofit management and leadership, planning, sociology, and tourism, among others (Bridger \& Luloff, 1999; Hamstead \& Quinn, 2005; Muthuri et al., 2012; Nikkhah \& Redzuan, 2010; Talmage et al., 2020; Theodori, 2005). Bridger and Luloff (1999) noted SCD's beginnings in the 1980s; SCD was used to describe strategies to address economic and population growth while minimizing negative environmental impact. They offered five components of sustainability, arguing that communities benefit from bolstering: (1) local economic diversity; (2) self-reliance; (3) proper energy use, recycling, and waste; (4) biological diversity and natural resources; and, (5) commitments to social 
justice. Importantly, they noted strong overlaps and interdependence among these components and provided a SCD framework.

Triple bottom line has been included in or paralleled SCD work (e.g., Dale \& Newman, 2010; Rogers \& Ryan, 2001). Dale and Newman (2010) posited three imperatives tying SCD to community well-being that mirror triple bottom line: (1) ecological - biodiversity and carrying capacity; (2) social - democratic systems and inclusiveness; and, (3) economic - meeting community needs and strengthening assets. These frameworks and models for increasing sustainability in CD efforts are important; however, drawing on Piggs and colleagues' (2013) insights, checkbox approaches may overlook the nuanced and interactive relationships among various community capitals; more scholarship is needed.

Two well-known and robust SCD approaches are: (1) the sustainable livelihoods framework; and, (2) the community capitals framework. The sustainable livelihoods framework (SLF) offers two important insights. First, SLF pushes for inclusive development, including the poor and the disenfranchised, specifically women, but also youth and elderly, ethnic and religious minorities, and differently abled people, among others. SLF efforts aim to benefit all community residents rather than reifying existing benefits for particular community elites. Second, SLF considers community resilience and asset-based approaches instead of only needs-based and reactive interventions (Gutierrez-Montes et al., 2009; Nel, 2015).

The community capitals framework describes different forms of capital that are interlinked within a community (Emery \& Flora, 2006; Gutierrez-Montes et al., 2009; Pigg et al., 2013). Many scholars and practitioners have adapted this framework and separated it into different domains (i.e., human capital and material capital). The domain of human capital often includes cultural, human, political, and social capitals. Social capital ${ }^{1}$ has most often been discussed in SCD work (Dale \& Newman, 2010; Zou et al., 2018), and cultural capital is often under-considered (Ashdown et al., 2020). The domain of material capital may include built, financial, and natural capitals. This article specifically focuses on the links between both domains via natural capital and cultural capital, and how focusing on these capital types can support SCD and uplift community well-being during and after the COVID-19 global pandemic.

Both SLF and community capitals have limits as frameworks. Community capitals should not be seen or used as accounting tools or checkboxes similar to the often-misused triple bottom-line approaches. Fittingly, Elkington (2018), who coined the term triple bottom line over 25 years ago, calls for it be abandoned as understandings of sustainability have evolved beyond the practical capabilities of this tool. Moreover, checkbox approaches fail to recognize and incorporate nuances among the different but interacting types of capital and, in turn, tend to especially undervalue natural capital and cultural capital. For example, focusing on livelihoods

\footnotetext{
1 While social capital appears inherently positive, scholars (e.g., Agnitsch et al., 2006; Flores et al., 2013) have suggested so-called dark side forms, such as gangs, mafias, mob organizations, white supremacy groups, cults, and illegal drug industries. These dark side forms also have overlaps with and impact cultural capital and natural capital.
} 
may overemphasize financial capital/well-being at the cost of other forms of capital/ well-being, such as natural capital and cultural capital.

Institutional and state-level limitations, mismanagement, and corruption, as well as social prejudices and elite capture of public resources, can undermine SLF efforts to achieve basic needs, such as access to resources like food, clean water, medicine, and shelter (Jackson, 2020). Combining sustainable livelihoods and community capitals, Cafer et al. (2019) highlight that system-level capacities can be easily overlooked by both frameworks. Such CD efforts may overly focus on resilience in specific parts of the community system rather than general resilience across the entire system. Also, such approaches can reify normative discourse.

We make the case that natural capital and cultural capital can pragmatically inform CD scholarship and practice in regard to sustainability and community wellbeing, particularly during and after the COVID-19 pandemic. What follows is an outline of the ties between both natural capital and cultural capital to community well-being, paying particular attention to quality of and access to these two types of capitals. Community cases are provided to demonstrate the nuanced interactions among nature, culture, and well-being, while paying attention to the large forces noted at the article's outset (e.g., climate change, global pandemics, racism, rising wealth inequality). In the conclusion, natural capital, cultural capital, CD, sustainability, and community well-being are brought together through questions and reflections.

\section{Why Natural Capital?}

"Never before has the need to aid nature's recovery, particularly in the face of the coronavirus (COVID-19) pandemic, been more urgent." - René Olivieri, Chair of The National Lottery Heritage Fund (Heritage Fund, 2020).

Natural capital's connection with community well-being is gaining traction in the scholarly literature (Allgood et al., 2019; Musikanski et al., 2020). Natural capital is the "living and nonliving components of ecosystems that contribute to the production of goods and services of value for people" (Guerry et al., 2015, p. 7349). Natural capital reaches across community capitals, from sourcing raw goods to enjoying leisure experiences. The goods and services that people derive from nature are also sometimes classified as ecosystem services, which have typically been divided into four categories: (1) Provisioning (e.g., those used in daily life like food, water, fiber, and fuel); (2) regulating (e.g., climate/carbon sequestration, pollination, and disease regulation/biological control); (3) habitat/supporting services (e.g., soil formation, nutrient cycling); and, (4) cultural services that nature can provide (e.g., education, cultural heritage, spirituality, recreation, and tourism; Harrison et al., 2014). Notably, the cultural services category of natural capital covers "the non-material, and normally non-consumptive, outputs of ecosystems that affect physical and mental states of people" (Fish et al., 2016, p. 209). Moreover, the four classifications of natural capital clearly highly overlap. For example, food is both a provision service, reliant on regulating and habitat/supporting services, yet craft food can be specifically cultural as a leisure/tourism service (Pascual et al., 2017). 
Nature's Contributions to People (NCP) is an ecosystem approach for examining natural capital in terms of ecosystem goods/services (Pascual et al., 2017). NCP embraces "concepts associated with [various] views on human-nature relations and knowledge systems" (Pascual et al., 2017, p. 15), including indigenous perspectives. NCP recognize strong links among indigenous territories, protected conservation areas, and planet biodiversity (Garnett et al., 2018; Schuster et al., 2019). Indigenous communities are essential stakeholders in protecting habitats and in biodiversity conservation. These communities have traditionally maintained a holistic relationship with nature and biodiversity, including cultural and spiritual community ties with animals and habitats, yet with fewer concerns about economic market valuation of natural capital compared to the valuation many non-indigenous societies have developed around natural capital.

The Nature-based Solutions (NbS) approach, articulated by the International Union for Conservation of Nature (IUCN), is another ecosystem approach. NbS is a system for harnessing nature and natural resources to address major social challenges. $\mathrm{NbS}$ promotes the sustainable use of nature for human needs, complementary to or in place of engineered solutions. Significantly, because the criteria that IUCN has developed for $\mathrm{NbS}$, it is incompatible with instrumental rationality (i.e., the achievement of a goal at any cost). NbS provides a straightforward, measurable framework for building resilient communities and improving human and environmental health and well-being - constructs that are going to be of utmost importance in a post-pandemic world. NbS offers a logical, stepwise process for approaching SCD work, predicated upon established norms to deliver societal benefits through protection, restoration, and sustainable management of natural ecosystems. ${ }^{2}$

Both NCP and NbS recognize that natural capital is intertwined with social and financial capital. Natural capital is linked with financial capital, for example, when the ecosystem-based goods and services natural capital provides are valued and sold in a market system and supply food, fiber, fuel, and other goods. The economic value of ecosystems is vast, although also vastly undervalued in the economic marketplace (De Groot et al., 2012). For example, communities can leverage the intersections among financial well-being, health equity, and climate by supporting green jobs, especially for young residents (Marmot, 2020). Notably, markets are not ethereal nor just and equitable; they are made up of decision-making social systems of humans. The absence of justice and equitable governance in markets often leads to the undervaluation of various forms of community capital. This undervaluation and/ or exploitation can leave the least resourced human communities without the goods or services they most need to survive and thrive financially and physically, as well as without the spiritual, cultural, and other social capital benefits of nature we previously noted. Thus, natural capital, like all forms of community capital, demonstrates links to social, economic, and environmental justice, which may be particularly apt during and after a global pandemic.

\footnotetext{
${ }^{2}$ For additional information on the IUCN definition and standards for NbS (i.e., eight criteria and 28 indicators), visit https://www.iucn.org/theme/ecosystem-management/our-work/iucn-global-standardnature-based-solutions
} 
Today, communities, especially those closest to wildlife and wild places, must be fully engaged to find successful outcomes for wildlife and people as quickly and effectively as possible to stem the extinction effects of the climate crisis as well as improve well-being in light of the global COVID crisis. Physical health, mental well-being, and improved happiness have all been linked to increased time spent with nature (Maller et al., 2006; Sandifer et al., 2015). During the COVID-19 pandemic, the Vermont Complex Systems Center daily mood analysis of 50 million tweets recently showed its lowest happiness levels since they began the project in 2008; however, they linked the presence of parks in communities to upticks in happiness levels similar to levels typical for the Christmas holiday season. Larger tree-filled parks provide the largest boost, but small neighborhood parks showed significant effects as well (Roman \& Ricketts, 2020) - highlighting the importance of natural capital for well-being during the pandemic and likely for a long period after the pandemic ends.

Natural capital in communities may help reduce health disparities, specifically through access to green space and nature (Marmot, 2020). Biodiversity and the natural environment in and around a community can increase a feeling of being rooted in a sense of place and connection for community members (Hausmann et al., 2016). Research establishing positive connections among nature, biodiversity, and wellbeing is important both to improve the lives of people and to improve outcomes for nature and biodiversity, which is increasingly at risk (Sandifer et al., 2015). ${ }^{3}$ Still, these connections will require honoring local cultural capital and utilizing natural capital to realize economic and social value.

\section{Why Cultural Capital?}

Cultural capital, similar to natural capital, is uniquely different from the financial structure of a community or society; yet, also like natural capital, it plays a vital role in the financial, social, and physical well-being of any community. When considering and discussing cultural capital, we do so similarly (though slightly differently) than economists have done for decades (Throsby, 1999), borrowing from earlier sociological ideas (Bourdieu, 1987). From this economic view, cultural capital is a resource that a community or society shares that illustrates their values, traditions, and perspectives. These resources, which can include items and concepts such as language, food, art, religious beliefs, agricultural techniques, and much else, are what members of a community or society have used to support their well-being and livelihoods.

Regarding cultural capital, the preservation and support of cultural capital represents the bedrock for community and individual well-being (Ashdown et al., 2020). This includes a sense of health, contentment, fulfillment, free will, and harmony that a community - usually living in the same location - have in common based on the aspects of cultural capital they share. Scholars have

\footnotetext{
${ }^{3}$ Extinction rates are the highest in human history with approximately a million plant species and animals threatened (IPBES, n.d.).
} 
established the relevance of cultural and location-specific issues for individual well-being (Panelli \& Tipa, 2007) and community well-being (Wiseman \& Brasher, 2008). The restraint, destruction, or diminishment of cultural capital can have detrimental effects on the well-being of community members (Ashdown et al., 2020), whether this is caused by unethical business practices, shortsighted international development, natural disasters, or global pandemics (Ashdown et al., 2020; Ashdown \& Buck, 2018; Miller \& Ashdown, 2020).

For CD to be sustainable and support the well-being of community members, cultural capital must be sustained. Cultural histories, traditions, and views - which have been utilized by communities for generations to create individual and community health - deserve the utmost respect and deference by SCD practitioners, scholars, and supporters (Ashdown \& Buck, 2018). It can be tempting to focus on other types of capital, especially financial capital, during and after the current global COVID pandemic. On one hand, it might seem obvious that government leaders and policymakers should focus on the ways that the pandemic are diminishing individual and community financial capital, and prioritize that over cultural capital. On the other hand, we might ask how people and communities can be expected to live their lives in the sustainable and healthy ways required to create and maintain financial capital if their cultural capital - that is, their ways of thinking about the world and their place in it - is severely diminished. And, if communities allow cultural capital (and natural capital) to wither during the pandemic, where will communities turn once life normalizes again?

\section{Sustaining Natural and Cultural Capital}

There are many examples of ways that communities and organizations are working hard (and often successfully) to sustain natural and cultural capital during the COVID pandemic. Museums have created virtual tours of their holdings (Romano, 2020), and the National Park Foundation in the US has developed online tours of various national parks (Watson, 2020). Not to be outdone by museums and national parks, lecture series (Stanley, 2020), libraries (Macaulay, 2020), concert series (Loop, 2020), and schools (Miller \& Ashdown, 2020) have all developed virtual, online programming to ensure that the natural and cultural capital of various communities are sustained, supporting the well-being of communities and community members.

What follows are cases from different areas of the world showcasing the intersections of natural and cultural capital. These cases generate insights that can improve $\mathrm{CD}$ approaches by harnessing natural capital and cultural capital to enhance community well-being. Leveraging the literature and theories, we critique the content found in these cases, with special emphasis on community capital(s) and well-being during and after the COVID-19 pandemic. Then, we conclude our article by offering questions and reflections for future research and practice. 


\section{Community Cases}

\section{Sedgemoor, Somerset, UK: Nature-Based Empowerment in Country Park}

Within Sedgemoor, Somerset, U.K., two large housing estates of over 4500 households called 'Wilstock' and 'Stockmoor' stand connected by a large flood plain and wetland called Country Park. ${ }^{4}$ The wetland was retained by the housing developers for its natural capital and biodiversity, which are accessible to residents in the community. Nearby to Country Park, but not within the aforementioned household area, stands a community with high levels of socioeconomic and health challenges, including child obesity (Bann et al., 2018). These residents also visit Country Park and can partake in the advantages of getting exercise and a change of environment - activities rooted in both cultural and natural capital. The interactions and connections among members of the two disparate household areas around the natural capital and asset that is Country Park provokes questions and discussions regarding social and environmental justice around access and care of people and nature.

The park was created and retained prior to the new 'mandatory biodiversity net gain' linked to the UK government's 25 Year Environment Plan, which requires new housing developments to deliver at least a $10 \%$ improvement in 'biodiversity value,' which should be on-site or adjacent to the housing development (Satin, 2020). Since the Lawton report in 2010, calls have echoed for the UK to make space for nature so that flora, fauna, and human life can thrive (Brotherton, 2020). In Country Park achieves these goals, as rare birds and waterfowl are seen and heard by residents. Fortunately, just prior to the COVID-19 pandemic, the developers constructed safe walkways around the small lake and for crossing the marshland.

During the pandemic lock down, many residents have sought reprieve from the related daily restrictions, and this small wilderness is frequently noted in Facebook exchanges. Residents remarked on the sight and sounds of the wildlife, which appeared to enhance the daily well-being of this community. They commented on how much it meant to see the wild birds, and celebrating their sightings on social media. Furthermore, recording wildlife in the area appears to be attractive and likely to grow, as reflected in the results of an October 2020 resident survey (blinded for review).

In the response to COVID-19 and the increased appreciation by the community members across both of the household areas, an asset-based community development (ABCD) approach (e.g., Harrison et al., 2019; Missingham, 2017) is underway. Residents have been consulted, with questions about their expressions of interest in being invited to learn more about nature and wildlife, as well as exploring new possibilities of potentially managing aspects of the park as a community, thus increasing opportunities to learn new land-based skills in the process.

The management of Country Park will be turned over to the local district council in 2022. Before then, various community-based organizations have become engaged

\footnotetext{
${ }^{4}$ Country Park is a pseudonym, and Country Park is still owned by the two developers, who built the nearby homes.
} 
in increasing the local population's awareness and responsibility use of the park. For example, Wilstockhub, ${ }^{5}$ a community-based charity, conducted the resident survey mentioned above and is overseeing the development a community hub in the area, which is organically developing links between local community and the natural and cultural capital asset that is Country Park. The district council and Wilstockhub will continue to explore opportunities to ensure the community can be constructively involved in a development and management plan for Country Park. This potential can be nurtured through future ABCD-based community engagement and by raising nature awareness. Additionally, a wildfowl and conservation organization has shown interest in working with Country Park, the council, and the community to further sustain the natural capital of the park. These synergies will ensure opportunities for learning about co-management by the community, thus enhancing biodiversity stewardship for all ages, maintaining local cultural capital, and building on the heightened interest of residents since the COVID-19 lockdowns. The participatory ABCD approach also has the potential to address the intersections of social justice and this community's current lack of resources beyond Country Park, further linking to environmental justice and wildlife justice.

Wilstockhub's approach in its work with Country Park epitomizes natural capitalbased empowerment of the local residents to address the intersections of social and environmental justice. The collaborative effort links experts and grassroots organizations together to build a sense of agency for residents to explore their own ideas as community stewards of Country Park as one of their biodiverse community assets. Nonetheless, these and future efforts should continue to aim to bolster social and environmental justice, the welfare of wildlife, and local well-being. These efforts can serve generations to come and may offer exemples of development efforts that interlink natural capital, specifically biodiversity, with local cultural capital in local SCD undertakings.

\section{UK Farmers: Gatekeepers of Natural Capital}

While many cities in the world have experienced severe impacts of the COVID-19 pandemic, rural areas have also been uniquely impacted (van Dorn et al., 2020). For example, farmers are experiencing the negative effects of social isolation. UK Farmers manage over $70 \%$ of UK land and are gatekeepers of substantial amounts of natural and cultural capital for their local communities; however, they are not often well-supported in these roles. Farmers are being tasked by individual, community, and government-mandated obligations to increase biodiversity, boost wildlife, and address climate change, while also navigating complex payment systems, regulations, and unstable weather patterns (Walker, 2020) - all during a global pandemic whose consequences will be felt for years.

A decrease of community capitals is apparent among farming communities during COVID-19, resulting in strong negative impacts. Meeting others at local markets

\footnotetext{
${ }^{5}$ For more on Wilstockhub, visit www.wilstockhub.com.
} 
and agricultural events used to be a vital form of cultural capital and interpersonal connection for agricultural workers. Many farmers had to destroy crops that could not be harvested, and dairy farmers, already facing intense challenges, had to dispose of vast quantities of milk. Destroying vital food supplies that could not be harvested due to COVID-19 was a highly traumatic experience for farmers (OECD, 2020). The effects of COVID-19 are especially worrisome given the high suicide rates typically found across rural UK farming communities, indicating persistent mental health disparities and potential lingering trauma (Kelly et al., 2020). Evidence gathered during the COVID-19 pandemic suggests that one farmer and/or farm worker in the UK commits suicide per week (McVey, 2020). While there are support systems within the farming community across the UK, more scholarship and practice insights are needed to help with these issues, specifically during the COVID-19 pandemic.

Organizations such as The Farming Community Network, who are acutely aware of the additional pressures resulting from COVID-19, have heard the call to help farmers with their mental health pressures. For example, a sign-posting service and helpline are offered through FarmWell, an organization that provides both personal and business resilience support related to COVID 19 impacts. The Nature Friendly Farming Network and Sustainable Food Trust (SFT) are organizations that offer opportunities for farmers to connect with expertise and support, while learning about and utilizing more sustainable farming methods. Both of these organizations aim to secure positive changes in policy and gain public support for farming using sustainability as theme to draw such support.

As the COVID-19 pandemic has brought about new challenges in farming and is demanding new ways of working to address impacts from the COVID-19 fallout, opportunities to increase awareness of sustainable farming, including regarding local wildlife and nature capital, are emerging. David Butler, a farmer in the Nature Friendly Farming Network (2020) states, "There is a place to find a sweet spot between production and wildlife... a balance of climate a balance of climate mitigation, nature recovery, and feeding people" (para. 10). SFT, in particular, has highlighted the positive outcomes of sustainable agricultural practices, such as better biodiversity, improved wildlife habitats, greater soil carbon sequestration, and more nitrogen fixation (Fitzpatrick et al., 2019).

Other organizations conduct essential global biodiversity and conservation research, including WildCRU, who write that, "biodiversity conservation requires an approach that bridges the gap between academic theory and practical problemsolving" (WildCRU, n.d., para 1). Biodiversity provides an important foundation for agricultural systems, with the conservation of biodiversity being critical for ensuring environmental sustainability - an important aspect of natural capital. At the same time, agriculture is playing a significant role in the biodiversity crisis by contributing to the major drivers of biodiversity loss in complex and interrelated ways.

Because of the COVID-19 pandemic, the pressures on agricultural production and producers (i.e., farmers) have never been greater and are only likely to accelerate current levels of biodiversity decline. Agricultural and food systems need innovation to care for cultivators and the natural and cultural capital they steward. One of these innovative practices to support farmers include the work done by Farm-Able 
Foundation, which matches farmers, via a mutual community/natural capital exchange. Matched volunteers may include military veterans and stressed health workers who can gain mental well-being benefits from nature while directly working with and practically supporting farmers. The Wildlife Trusts and other similar organizations are exploring co-designed models, ${ }^{6}$ that can enhance communities' connections with nature, also called green social prescribing, ${ }^{7}$ to push for greater well-being coupled with more sustainable futures for communities. Thus, wellness, at least for farmers, includes inextricable connections between the cultural capital of rural life and the stewardship of the natural capital (i.e., food, wildlife, etc.), which many communities enjoy.

\section{A Community in Kenya: The Maa Trust ${ }^{8}$}

Communities must be engaged to protect wildlife on their own lands, and on adjacent national park lands to truly protect wildlife. Kenya has a long history of wildlife conservation, with $65 \%$ of wildlife in Kenya found outside the network of government-protected areas, on private or community land (Western et al., 2009). Wildlife conservation has gone through several phases, and throughout most of Kenya's history, communities have been excluded from the management and benefits of wildlife conservation.

From the colonization period in Kenya (1890s) through the establishment of the national parks (1945) and until very recently, Kenya's relationship with communities and conservation has been characterized by the general exclusion of communities from decision-making about and benefits from parks and wildlife, denying these communities many of the benefits of natural and cultural capital. The creation of the Kenya Wildlife Service began a period of a gradual transition to more community involvement in conservation and attempts to move to community conservancies as a way to empower communities to truly have responsibility for their wildlife and land (Cockerill \& Hagerman, 2020) and to enjoy the benefits of that natural and cultural capital. The Kenyan Wildlife Act (27th December 2013) ${ }^{9}$ was passed so that individual and community landowners can establish sanctuaries or conservancies for wildlife.

\footnotetext{
${ }^{6}$ For more on those emerging efforts, visit www.communityhealthinternational.co.uk.

${ }^{7}$ For more on The Wild Life Trusts visit (https://www.wildlifetrusts.org), and for more on green social prescribing visit (https://www.rhs.org.uk/advice/health-and-wellbeing/articles/social-prescribing).

${ }^{8}$ For more on The MAA Trust visit: https://www.themaatrust.org/. Other projects addressed by the trust include: Addressing child marriage, child pregnancy, female genital mutilation and child labor, which are major factors causing school drop outs; addressing causes of children not being in school, and improving the quality of education in the Maasai Mara; working to address youth unemployment through vocational training and career guidance; proving entrepreneurship skills training that teaches women and youth to create their own micro-business and employ themselves; and constructing water projects in schools and communities, relieving the burden of water collection from women and girls.

${ }^{9}$ For full information visit, http://kenyalaw.org/kl/fileadmin/pdfdownloads/Acts/WildlifeConservation andManagement\%20Act2013.pdf.
} 
As of 2016, Kenya has approximately 160 conservancies, mostly on community land (KWCA, 2016). Individuals and communities may choose to establish conservancies or sanctuaries for various social, environmental, and/or economic reasons such as: (1) upholding tradition and culture; (2) endangered species protection; and (3) diversification of income-generation. Before 2013, no legislation outlined a specific model for conservancy; hence, many different models of conservancies operate in Kenya today (King et al., 2015). Conservancies and conservancy initiatives create sustainable livelihoods while decreasing declines in wildlife. "In the Maasai Mara, for example, fifteen conservancies protect over 450,000 acres of a critical habitat for the great Serengeti-Mara wildebeest migration" (KWCA, 2020, para 6).

Beginning in 2006, Maasai elders invited representatives from many different conservation groups to collaborate with them to form conservancies to increase benefits of tourism and for local communities and wildlife related to cultural and natural capital. The Maa Trust works closely with conservancies in the Maasai Mara on SCD work that complements conservancy efforts across the Maasai Mara. All projects undertaken by The Maa Trust are based on needs assessments and the desires of the local Maasai people. For example, Maa Beadwork and Maa Honey social enterprises provide vital incomes for Maasai women. Socio-economic development empowers women and helps them to save for essential items and to participate in micro-credit programs. Maasai elders also called upon the Maa Trust for help in developing a program to improve schools and develop vocational training opportunities for youth.

Before the COVID-19 pandemic, The Maa Trust received \$5 per guest per night from various camps within neighboring conservancies. Tourism operators supported The Maa Trust to ensure that the benefits of conservancies extend beyond just male landowners, to also reach to women, youth and children. Near the northern Maasai Mara National Park, 15 conservancies cover nearly 1500 square-kilometers. In 2018, 40 tourism outfits leased land from the Maasai Mara Conservancies from 14,500 local Masai landowners, generating employment for the area. Money generated from guests is also used to provide local health and educational services (Thoumi \& Waugh, 2018). In the Maasai Mara, this funding is provided through a bed-night donation to The Maa Trust. This partnership between the Maa Trust and ecotourism sector ensured more local communities enjoyed the benefits from their shared natural and cultural capital.

Unfortunately, the COVID-19 pandemic has devastated the ecotourism revenue on which the community projects depended and upended the community progress towards better well-being for all. With tourism shut down, the support garnered from tourism was lost. Visitors are no longer buying the beautiful beadwork the women entrepreneurs produced and lodges are no longer buying their honey. Before the pandemic, international tourism represented approximately $2 \%$ of GPB $(\sim \$ 1.6 \mathrm{~B})$ in Kenya, and was undergirded by over 1,000 hotel/hospitality establishments (e.g., safari lodges run by families); however, this number is expected to dip below 1,000 establishments post-COVID-19.

The COVID-19 economic ecotourism shutdown puts additional pressure on the world-renowned wildlife and environment of the Maasai Mara, and there is concern that intensive agricultural practices may begin to take over wild habitats. Poaching 
of wildlife for food and money are increasing. These shifts in land usage and care will make the recovery of ecotourism very difficult, which could create more difficulties for communities that reliant on their natural and cultural capital to engage in ecotourism to recover. Thus, it is critical that communities who have engaged with tourism to find immediate relief for their basic needs, and then long-term solutions for diversified SCD if COVID-19 related challenges are resolved in ways that do not bring back ecotourism economies. Most troubling of all is that with children unable to attend school during the COVID-19 pandemic, female genital mutilation, child pregnancy, and child marriage are all on the increase. Families are desperate for money to survive and the human rights of the weakest in these communities are most at risk. Ensuring that these communities are able to rely on their own natural and cultural capital will be vital to safeguard their continued well-being.

\section{The Navajo Nation: Removing Colonial Constructs from Natural and Cultural Capital}

Health and well-being disparities are being exacerbated during the COVID-19 pandemic, showcasing inequitable impacts on people of color in the US, especially among Native American nations (CDC, 2020). Such statistics provide a Western lens on the overall outcomes of COVID-19, which analyzes epidemiological evidence from within high population areas by choosing densely populated areas that lead to narratives that (mis)represent per capita evidence in the case of Tribal nations. Western-trained researchers typically miss rich narratives, data, and lenses as they tend to ignore the use of indigenous methodologies (Kovach, 2010). Evidence and narratives about the COVID-19 pandemic must be presented not only from the USA federal government, but also indeed from the governing nation's leadership (Tsosie, 2020).

The Navajo Nation, a sovereign and federally recognized Nation of the Diné people, represents the largest Native American population in the USA, as well as the largest area of land mass intersecting with the states of Arizona, Colorado, New Mexico and Utah (Kennedy et al., 2017). Land is considered sacred to the Diné people, and families are grouped by clans throughout 110 unique chapters as political subdivisions of the Navajo Nation (Gardner et al., 2013). Whereas the land is considered sacred for food, shelter, water, and ceremony, family living arrangements respect the land and utilize communal housing arrangements for multiple generations in hogans (octagonal round homes), traditional western homes, and other living quarters. Protecting and living off of the land represents the connection between the Diné and the natural and cultural capital of the land's vast base of minerals, food, medicine, water, wildlife, and sacred areas (Gardner, et al., 2013; Zaferatos, 2015).

While the Navajo Nation values their land as a sacred cultural asset, the nation and its land have faced grave challenges regarding self-determination and selfsufficiency. These challenges stem from different unique restrictions about subsurface mining rights, pollution from uranium and coal mining, different development restrictions, easements throughout the Nation, and a lack of various community capitals because of the inability to develop financial institutions (Gardner et al., 2013). 
Because of these challenges and the long-term colonialist destruction of Diné natural and cultural capital, the Navajo Nation often finds itself dependent on resources from outside their communities.

The Navajo Nation is resilient and has survived genocide, USA oppression, and pandemics, showing an ability to respond to challenges when they are able to plan for their future (Akee \& Jorgensen, 2014). When these communities are able to use their traditional knowledge and their natural and cultural capital, they enjoy higher levels of economic wealth and overall quality of life (Trevan, 2016). The Navajo Nation experienced one of the worst outbreaks of COVID-19 in the USA (Parshley, 2020). Because of the dependency of the Navajo Nation on resources from outside its boundaries caused by centuries of damage to their community capitals, COVID19 was able to enter Diné communities via tourists, fast food locations, supplies, clothing, and fuel. Because outside groups have created so many obstacles and challenges for the Diné to utilize their own natural and cultural capital, these communities were not able to utilize their full environment and resources in the best interest of the Nation, resulting in the devastating consequences of the COVID-19 pandemic.

Outside groups and influences must provide space for the Navajo Nation to fully engage with their natural and cultural capital, particularly in four areas: (1) community capacity; (2) planning resources; (3) tribal governance; and (4) comprehensive planning (blinded for review). To address the consequences of the outbreak of COVID-19 and its aftermath among the Diné, as well as the discriminatory effects of the pandemic, colonial constructions and biased US policy must change to ensure the Navajo Nation's land is governed by and used as a natural and cultural capital asset for the Diné. Elevating awareness of the effects of the COVID-19 pandemic among Tribal nations as described by their own narratives and data, especially among the Diné, and demonstrating how the pandemic has and will continue to affect these collective family-based societies and traditional native cultures is necessary. This will highlight the disconnection between the Western US narrative of the COVID-19 pandemic impacting jobs and entertainment, and make it clearer how the pandemic is impacting traditional forms of livelihood (Tsosie, 2020), including the natural and cultural capital resources of religion, employment, farming, and hunting, resulting in elevating the COVID-19 narratives of indigenous nations above statistics and other forms of data aggregation (Mullen, 2020).

\section{California Wildfires: Prescribed Burns to Protect Cultural and Natural Capital}

Recent unprecedented California wildfires have been attributed to climate change (Tripp, 2019). Media coverage of wildfires generally depicts them as natural disasters, which spins the narrative that the locals do not have control of the wild land (Tripp, 2019). In addition, the politically loaded phrase 'climate change' can amplify the fear of fire in communities (Tripp, 2019) and creates the view that these fires have become inevitable (Tripp, 2019), leaving residents with the belief that little can be done to mitigate these events. However, a substantial underlying contributor to the wildfires can be managed and has been managed for centuries (Tripp, 2019); that contributor is inadequate wildfire suppression strategies. 
Brush overgrowth in the forests serves as fuel for the fires, but this overgrowth was not as prominent 150 years ago because indigenous persons initiated prescribed burns in the area to maintain the land (Lee, 2020a). Indigenous tribes have long set low-intensity fires to control eco-cultural resources and reduce the buildup of fuels, flammable trees, grasses and brush, which cause bigger, hotter and more destructive fires, such as those that have burned through the Western US in recent years (Lee, 2020b).

Forest management, an example of directly protecting natural capital, can be enhanced by drawing on the knowledge of indigenous tribes building cultural capital, and modernizing public knowledge of wildfires. Indigenous persons have called for bringing fire back to the land (Lee, 2020b). Traditionally, fire was not perceived as the igniter of brush fires, rather as a tool for producing food and increasing plant life to create materials such as rope and baskets. Fire was also used for spiritual rituals to lift up prayer, keeping the land in check. By suppressing fire, the spiritual connection, cultural capital, and sustainable lifestyle of the forest is significantly impacted (Lee, 2020b).

Culturally-based burning largely vanished after Western settlers forced indigenous persons from their homes and banned sacred burning rituals (Lee, 2020b). State and federal officials concentrated on rapidly extinguishing wildfires. But fire suppression has only increased the risk of wildfires in California. The landscape grows dense with vegetation that dries out every summer without frequent burns, providing fuel for the fires that frequently devastate California neighborhoods (Sommer, 2020). Thus, new alliances are being forged between tribal leaders and government officials. To minimize the likelihood of devastating wildfires, state and federal land managers recognize that they have hundreds of thousands of acres that require attentive burning (Sommer, 2020), and in order to reclaim traditional burns, indigenous groups are hopeful of obtaining better access to those ancestral lands once again to mitigate the devastating wildfires (Lee, 2020b).

Unfortunately, however, conflict between indigenous groups and state and federal officials in California remains (Lee, 2020b). While systematic discrimination and exclusion of indigenous persons is readily apparent (Lee, 2020b), the conflict around wildfires can be understood in terms of knowledge of and interaction with the natural and cultural capital asset that is the forest. The conflict is rooted in claimed differences between so-called expert and indigenous knowledge; however, those differences may not be as vast as they seem on their face. Officials and policies demand that tribes receive licenses before burning and can forbid practices out of concerns for potential air quality issues, liability, and out-of-control fires. Indeed, fire experts claim that before forest fires lead to even more destruction of natural and cultural capital, particular California forest areas should be thinned out (Fuller, 2020). Indigenous traditions look to nature for signs on when it is appropriate to start prescribed burns. It is vital not to disturb natural fire breeding cycles, nesting birds, or flowering plants, but to burn in ways that promote essential plant growth, such as for hazelnut bushes and acorn-bearing oaks (Fuller, 2020). Different species experience wildfires differently, which must be considered (Gorman, 2020). Non-indigenous expert knowledge leverages other indicators and methods, but it can (and should) be coupled with indigenous 
knowledge to determine when a prescribed burn is safe and appropriate for all local residents - humans, animals, and plants alike.

As an ecological aspect and conservation strategy, federal, state and local government entities are progressively embracing indigenous burning (Lee, 2020b). These governments and indigenous communities acknowledge that the climate change crisis creates an incentive for land managers to address harmful socio-ecological behavior and to establish fruitful relationships to facilitate sustainability and protect natural and cultural capital. Colonialism and the neglect of indigenous conservation has caused incredible damage to indigenous populations and created a social-ecological environment in which it is more difficult, under existing legal and political constraints, to pursue the very activities that improve habitats. The Karuk Climate Adaptation Plan has seen as a helpful example (Tripp, 2019). Opportunities for bridging and linking indigenous knowledge and non-indigenous knowledge exist to address the destructive wildfires in the Western US, which will annually occur.

\section{Where Do We Go from Here for Post-COVID-19?}

You can have all the natural capital you can imagine and if the communities are locked out of it, you will not have community resilience. - blinded for review

Returning to our four major forces of global change (i.e., climate change, COVID19 , racism and cultural ethnocentrism, and wealth inequality), the need for access to and care of natural and cultural capital across communities could not be greater regarding community well-being. The community cases exemplify the strong links between natural capital and cultural capital. The COVID-19 pandemic has not only led to stark challenges for hospitals regarding physical health, but also global mental health disparities, which are impacting well-being. Each case touched on pieces of the four major forces, as well as themes from the community capitals, sustainable livelihoods, NCP, and NbS frameworks.

Now is the time to reimagine our relationship with nature and culture and to bolster sustainability. Shifts in mindsets will be necessary to not only consider what natural and cultural capital can do to improve well-being, but also how improving nature can enhance natural capital, cultural capital and well-being simultaneously and symbiotically. Indigenous knowledge, local community experts, and heterogeneous partnerships will be necessary aspects of any successful plan. Policies will need to change and SCD strategies will need to be retooled. Vulnerabilities, strengths, and resilience must be considered.

Reflecting on the cases, questions are offered for future research, policy, and practice (see Table 1). These questions are not all-encompassing, but provide starting points for bolstering community well-being and sustainability by tethering together natural capital and cultural capital in research, policy, and practice. Table 1 is organized by themes unearthed in this article.

As many have said, with crisis comes opportunity. With many communities under quarantine/lockdown due to the Covid-19 pandemic, animals are being seen 
Table 1 Questions for intentionally tethering natural capital and cultural capital

\begin{tabular}{|c|c|}
\hline Theme & Question(s) \\
\hline Attachment to Land & $\begin{array}{l}\text { How is the attachment to the community land expressed and realized? Who } \\
\text { are the stewards of the land and its resources? What role does the land play } \\
\text { in the community's cultural worldview? }\end{array}$ \\
\hline Ecosystem Approaches & $\begin{array}{l}\text { Which ecosystem approaches, such as NCP or NbS, may benefit current } \\
\text { understandings of community capitals and livelihoods? }\end{array}$ \\
\hline Elite Influence & $\begin{array}{l}\text { Who are those who are benefiting from the current equilibrium? How can } \\
\text { they be persuaded to share/relinquish the benefits they are reaping from the } \\
\text { current equilibrium, which is likely unjust? How do current cultural values } \\
\text { support the existing equilibrium, and should those values be addressed? }\end{array}$ \\
\hline Enterprise & $\begin{array}{l}\text { How can enterprise efforts, such as ecotourism, be bolstered apart from } \\
\text { emergency aid to build in community resilience while respecting existing } \\
\text { cultural worldviews? }\end{array}$ \\
\hline Forces & $\begin{array}{l}\text { How can climate change, pandemic vulnerability, economic vulnerability, } \\
\text { and racism/ethnocentrism be examined together instead of separately in } \\
\text { regard to natural and cultural capital? }\end{array}$ \\
\hline Health & $\begin{array}{l}\text { How can understandings of mental and physical health benefit from authen- } \\
\text { tic considerations of natural and cultural capital? }\end{array}$ \\
\hline Indigenous Knowledge & $\begin{array}{l}\text { Who are the keepers of indigenous knowledge? How can indigenous knowl- } \\
\text { edge complement non-indigenous discovery? How can the cultural capital } \\
\text { of both indigenous and non-indigenous communities be combined for } \\
\text { maximum benefit? }\end{array}$ \\
\hline Local Culture and History & $\begin{array}{l}\text { Who are the keepers of local culture and history? How can local culture and } \\
\text { history be leveraged for substantial change? }\end{array}$ \\
\hline Meaning and Purpose & $\begin{array}{l}\text { How do community members and visitors make meaning and find purpose } \\
\text { regarding the natural and cultural capital found in communities? }\end{array}$ \\
\hline Outsider vs. Insider & $\begin{array}{l}\text { What are the discrepancies between outsider and insiders regarding benefit- } \\
\text { ing from local resources or influencing the use of local resources? How } \\
\text { should cultural worldviews influence the way outsiders are welcomed (or } \\
\text { not) into a community? }\end{array}$ \\
\hline Participation & $\begin{array}{l}\text { How can inclusive approaches be practiced to ensure all community mem- } \\
\text { bers have a say regarding how natural capital and cultural capital is utilized } \\
\text { in their communities? }\end{array}$ \\
\hline Past Trauma & $\begin{array}{l}\text { How can historical and more recent marginalization of community members/ } \\
\text { groups be appropriately recognized when working towards development } \\
\text { around natural and cultural capital? }\end{array}$ \\
\hline Sustainability & $\begin{array}{l}\text { Who decides what determines success regarding sustainability efforts? How } \\
\text { are concerns about both natural capital and cultural capital included in } \\
\text { these determinations? }\end{array}$ \\
\hline Vulnerability & $\begin{array}{l}\text { How can those most vulnerable (human and non-human) receive care and } \\
\text { support? }\end{array}$ \\
\hline Wildlife & $\begin{array}{l}\text { Where is the place for wildlife in the ecosystem? How is its presence hon- } \\
\text { ored, welcomed, and nurtured? How can we ensure wildlife is considered } \\
\text { as a both natural capital and cultural capital? }\end{array}$ \\
\hline
\end{tabular}

in communities where they have not been seen regularly, and people are excited. Air and water is cleaner and clearer from substantially less use of motorized transportation (though still not down enough to meet climate goals). And people want to be 
out in nature more. Now is the time to nurture humanity's cultural relationship with natural capital in research, policy, and practice. For far too long, they have been measured separately when they have remained across time inextricably intertwined.

\section{Declarations}

Conflict of Interest There are no conflicts of interest for this article to declare.

\section{References}

Agnitsch, K., Flora, J., \& Ryan, V. (2006). Bonding and bridging social capital: The interactive effects on community action. Community Development, 37(1), 36-51.

Akee, R., \& Jorgensen, M. (2014). Property institutions and business investment on American Indian reservations. Regional Science and Urban Economics, 46, 116-125.

Allgood, B., Hofberg, M., Musikanski, L., Michelini, L., \& Moser, M. (2019). Assessing communitybased wildlife conservation programs with the gross national happiness framework. International Journal of Community Well-Being, 2(3), 301-337.

Ashdown, B. K., \& Buck, M. (2018). International aid as modern imperialism-What does cross-cultural psychology really have to offer? A commentary on "the positive role of culture: What cross-cultural psychology has to offer to developmental aid effectiveness research" by Symen A. Brouwers. Journal of Cross-Cultural Psychology, 49, 545-553. https://doi.org/10.1177/0022022118768428

Ashdown, B. K., Dixe, A., \& Talmage, C. A. (2020). The potentially damaging effects of developmental aid and voluntourism on cultural capital and well-being. International Journal of Community WellBeing. https://doi.org/10.1007/s42413-020-00079-2

Bann, D., Johnson, W., Li, L., Kuh, D., \& Hardy, R. (2018). Socioeconomic inequalities in childhood and adolescent body-mass index, weight, and height from 1953 to 2015: An analysis of four longitudinal, observational, British birth cohort studies. The Lancet Public Health, 3(4), e194-e203. https://doi. org/10.1016/S2468-2667(18)30045-8

Bhattacharyya, J. (2004). Theorizing community development. Community Development, 34(2), 5-34.

Bourdieu, P. (1987). Distinction: A social critique of the judgment of taste. Routledge.

Bridger, J. C., \& Luloff, A. E. (1999). Toward an interactional approach to sustainable community development. Journal of Rural Studies, 15(4), 377-387.

Brotherton, P. (2020, September 16). Making space for nature - 10 years on. Natural England (blog). Retrieved 16 November 2020 from https://naturalengland.blog.gov.uk/2020/09/16/ making-space-for-nature-10-years-on/

Cafer, A., Green, J., \& Goreham, G. (2019). A community resilience framework for community development practitioners building equity and adaptive capacity. Community Development, 50(2), 201-216.

Center for Disease Control and Prevention [CDC]. (2020, Jul 24). Health equity considerations \& racial $\&$ ethnic minority groups. Center for Disease Control and Prevention. Retrieved 25 August 2020 from https://www.cdc.gov/coronavirus/2019-ncov/community/health-equity/race-ethnicity.html.

Cockerill, K., \& Hagerman, S. (2020). Historical insights for understanding the emergence of community-based conservation in Kenya: International agendas, colonial legacies, and contested worldviews. Ecology and Society, 25(2), 15.

Dale, A., \& Newman, L. (2010). Social capital: A necessary and sufficient condition for sustainable community development? Community Development Journal, 45(1), 5-21.

De Groot, R., Brander, L., Van Der Ploeg, S., Costanza, R., Bernard, F., Braat, L., et al. (2012). Global estimates of the value of ecosystems and their services in monetary units. Ecosystem Services, 1(1), 50-61.

Elkington, J. (2018, June 25). 25 years ago I coined the phrase “Triple Bottom line." Here's why it's time to rethink it. Harvard Business Review. Retrieved July 17, 2020 from: https://hbr.org/2018/06/ 25-years-ago-i-coined-the-phrase-triple-bottom-line-heres-why-im-giving-up-on-it.

Emery, M., \& Flora, C. (2006). Spiraling-up: Mapping community transformation with community capitals framework. Community Development, 37(1), 19-35. 
Fish, R., Church, A., \& Winter, M. (2016). Conceptualising cultural ecosystem services: A novel framework for research and critical engagement. Ecosystem Services, 21, 208-217.

Fitzpatrick, I., Young, R., Barbour, R., Perry, M., Rose, E., \& Marshall, A. (2019). The hidden cost of UK food: Revised edition 2019. Sustainable food trust. Retrieved 22 November 2020 from https:// sustainablefoodtrust.org/wp-content/uploads/2013/04/Website-Version-The-Hidden-Cost-of-UKFood.pdf.

Flores, D. V., Torres, L. R., Torres-Vigil, I., Ren, Y., Haider, A., \& Bordnick, P. S. (2013). "El lado oscuro": "The dark side" of social capital in Mexican American heroin using men. Journal of Ethnicity in Substance Abuse, 12(2), 124-139.

Fuller, T. (2020, January 29). Native solutions to big fires: Cultural burning practices are working to reduce wildfires in northern Australia. Can they work in California, too? The New York Times. Retrieved 17 November 2020 from https://www.nytimes.com/2020/01/24/us/native-american-contr olled-burns-california-wildfires.html.

Gardner, J, Pijawka, D, Trevan, E, (2013). Review and recommendations for updating the community based land use plans for the Navajo nation, School of Geographical Sciences and Urban Planning, Arizona State University, Tempe, Arizona. Technical Report. Retrieved 16 November 2020 from http://www.nndcd.org/uploads/FileLinks/7941e9e8c4b3492ca06e56dbe5e5f3fe/2013_11_21_10_ 36_34_ASU_Study.pdf.

Garnett, S. T., Burgess, N. D., Fa, J. E., Fernández-Llamazares, Á., Molnár, Z., Robinson, C. J., ... \& Collier, N. F. (2018). A spatial overview of the global importance of indigenous lands for conservation. Nature Sustainability, 1(7), 369-374.

Gorman, S. (2020 October 8). Rescue network seeks to save, rehab California's fire-stricken wild animals. Reuters. Retrieved 22 November 2020 from https://www.reuters.com/article/us-usa-wildfires-wildl ife/rescue-network-seeks-to-save-rehab-californias-fire-stricken-wild-animals-idUSKBN26T1MZ.

Guerry, A. D., Polasky, S., Lubchenco, J., Chaplin-Kramer, R., Daily, G. C., Griffin, R., et al. (2015). Natural capital and ecosystem services informing decisions: From promise to practice. Proceedings of the National Academy of Sciences, 112(24), 7348-7355.

Gutierrez-Montes, I., Emery, M., \& Fernandez-Baca, E. (2009). The sustainable livelihoods approach and the community capitals framework: The importance of system-level approaches to community change efforts. Community Development, 40(2), 106-113.

Hamstead, M. P., \& Quinn, M. S. (2005). Sustainable community development and ecological economics: Theoretical convergence and practical implications. Local Environment, 10(2), 141-158.

Harrison, P. A., Berry, P. M., Simpson, G., Haslett, J. R., Blicharska, M., Bucur, M., et al. (2014). Linkages between biodiversity attributes and ecosystem services: A systematic review. Ecosystem Services, 9, 191-203.

Harrison, R., Blickem, C., Lamb, J., Kirk, S., \& Vassilev, I. (2019). Asset-based community development: Narratives, practice, and conditions of possibility-A qualitative study with community practitioners. SAGE Open, 9(1), 2158244018823081.

Hausmann, A., Slotow, R. O. B., Burns, J. K., \& Di Minin, E. (2016). The ecosystem service of sense of place: Benefits for human well-being and biodiversity conservation. Environmental Conservation, 43(2), 117-127.

Heritage Fund. (2020, Jul 23). Farmers at heart of groundbreaking nature recovery project. Heritage Fund UK. Retrieved 26 August 2020 from https://www.heritagefund.org.uk/news/farmers-heart-groun dbreaking-nature-recovery-project.

International Intergovernmental Science-Policy Platform on Biodiversity and Ecosystem Services (IPBES). (n.d.). Nature's dangerous decline 'unprecedented' species extinction rates 'accelerating'. Retrieved 17 August 2020 from https://ipbes.net/news/Media-Release-Global-Assessment\#: :text= The $\%$ 20IPBES\%20Global\%20Assessment\%20Report,innovative\%20ways\%20of\%20 evaluating\% 20evidence.

Jackson, E. A. (2020). Deconstructing sustainable livelihood framework (SLF) for equitable living in crisis of global pandemic. Technical Report. MPRA Paper No. 101977. Retrieved 9 August 2020 from https://mpra.ub.uni-muenchen.de/101977/1/MPRA_paper_101977.pdf.

Kelly, M., Ventriglio, A., \& Bhugra, D. (2020). Mental health aspects of rural living. In S. K. Chaturvedi (Ed.), Mental health and illness in the rural world (pp. 17-30). Springer Nature Singapore.

Kennedy, D. M., Harrington, C. F., \& Verbos, A. K. (2017). In D. Stewart, J. S. Gladstone, \& G. Clarkson (Eds.), American Indian business: Principles and practices. University of Washington Press. 
Kenya Wildlife Conservancies Association (KWCA). (2016). State of wildlife conservancies in Kenya 2016. KWCA. Technical Report. Retrieved 16 November 2020 from https://kwcakenya.com/wpcontent/uploads/2018/01/SoC-Report.pdf.

Kenya Wildlife Conservancies Association (KWCA). (2020). Overview. KWCA. Retrieved 16 November 2020 from https://kwcakenya.com/conservancies/.

King, J., Kaelo, D., Buzzard, B., \& Warigia, G. (2015). Establishing a wildlife conservancy in Kenya. Kenya wildlife conservancies association. Retrieved 16 November 2020 from https://sgp.undp.org/ all-documents/country-documents/911-establishing-a-wildlife-conservancy-in-kenya/file.html.

Kovach, M. (2010). Indigenous methodologies: Characteristics, conversations, and contexts. University of Toronto Press.

Lee, S. Y. (2020a, May 28). Climate crisis likely to lead to global economic collapse. Earth.org. Retrieved 17 August 2020 from https://earth.org/climate-crisis-could-collapse-the-global-economy/.

Lee, T. (Host). (2020b, September 2017). Into reclaiming fire to save the forest. Into America [Audio podcast]. MSNBC. https://www.msnbc.com/intoamerica. Accessed 29 Nov 2021.

Loop, T. T. (2020). Take Your Mind Off COVID-19 with These Virtual Concert Series. Take your mind off COVID-19 with these virtual concert series I Loop News (looptt.com). https://tt.loopnews.com/conte nt/take-your-mind-covid-19-these-virtual-concert-series. Accessed 29 Nov 2021

Macaulay, D. (2020, October 14). Local libraries make transition to online. Pilot Online. https://www. pilotonline.com/news/education/vp-br-portsmouth-libraries-1018-20201014-r65otqdvhfbphkr zmxnexxva2y-story.html. Accessed 29 Nov 2021.

Maller, C., Townsend, M., Pryor, A., Brown, P., \& St Leger, L. (2006). Healthy nature healthy people: 'Contact with nature' as an upstream health promotion intervention for populations. Health Promotion International, 21(1), 45-54.

Marmot, M. (2020, June 23). Using Marmot principles to tackle health inequalities and COVID-19, 23 June 2020 [webinar]. Local government association. Retrieved 26 August 2020 from https://www. local.gov.uk/using-marmot-principles-tackle-health-inequalities-and-covid-19-23-june-2020.

McVey, R. (2020, Aug 6). Mental health study ramped up as COVID-19 takes toll on farmers. The Press and Journal. Retrieved 23 September 2020 from https:/www.pressandjournal.co.uk/fp/news/aberd een/2387266/mental-health-study-ramped-up-as-covid-19-struggles-take-toll-on-farmers/.

Miller, S. M., \& Ashdown, B. K. (2020). When COVID affects the community: The response of a needsbased private school in Guatemala. Local Development \& Society, Online Article. https://doi.org/10. 1080/26883597.2020.1794758

Missingham, B. D. (2017). Asset-based learning and the pedagogy of community development. Community Development, 48(3), 339-350.

Mullen, C. A. (2020). What does Canadian indigenous literature impart about colonization and the future? In the educational forum (pp. 1-18). Routledge.

Munro, A., Boyce, T., \& Marmot, M. (2020). Sustainable health equity: Achieving a net-zero UK. Institute of Health Equity. Technical Report. Retrieved 16 November 2020 from http://www.instituteofheal thequity.org/resources-reports/sustainable-health-equity-achieving-a-net-zero-uk/main-report.pdf.

Musikanski, L., Allgood, B., Hofberg, M., Atema, K. N., Trevan, E., \& Phillips, R. (2020). Proposing a community-based wildlife conservation well-being instrument. International Journal of Community Well-Being, 1-21. Retrieved 17 August 2020 from. https://doi.org/10.1007/s42413-020-00069-4

Muthuri, J. N., Moon, J., \& Idemudia, U. (2012). Corporate innovation and sustainable community development in developing countries. Business \& Society, 51(3), 355-381.

Nature Friendly Farming Network. (2020). David Butler (interview). Nature friendly farming Network. Retrieved 16 November 2020 from https://www.nffn.org.uk/wp-content/uploads/2020/07/21823NFFN-Case-Study-Leaflets_DAVID-BUTLER-18-06-20.pdf.

$\mathrm{Nel}, \mathrm{H}$. (2015). An integration of the livelihoods and asset-based community development approaches: A south African case study. Development Southern Africa, 32(4), 511-525.

Nikkhah, H. A., \& Redzuan, M. R. B. (2010). The role of NGOs in promoting empowerment for sustainable community development. Journal of Human Ecology, 30(2), 85-92.

OECD. (2020, April 29). COVID-19 and the food and agriculture sector: Issues and policy responses. OECD Policy Responses to Coronavirus (COVID-19). Retrieved 26 August 2020 from https://www. oecd.org/coronavirus/policy-responses/covid-19-and-the-food-and-agriculture-sector-issues-andpolicy-responses-a23f764b/.

Outdoor Foundation. (2019). 2019 outdoor participation report. Outdoor Foundation. Retrieved 27 August 2020 from https://outdoorindustry.org/resource/2019-outdoor-participation-report/ 
Panelli, R., \& Tipa, G. (2007). Placing well-being: A Maori case study of cultural and environmental specificity. EcoHealth, 4, 445-460. https://doi.org/10.1007/s10393-007-0133-1

Parshley, L. (2020, Jul 28). How the Navajo nation slowed one of the worst Covid-19 outbreaks in the US. VOX. Retrieved 25 August 2020 from https://www.vox.com/2020/7/28/21344969/covid-19masks-arizona-new-mexico-utah-navajo-nation.

Pascual, U., Balvanera, P., Díaz, S., Pataki, G., Roth, E., Stenseke, M., et al. (2017). Valuing nature's contributions to people: The IPBES approach. Current Opinion in Environmental Sustainability, 26, 7-16.

Phillips, R., \& Pittman, R. H. (2009). A framework for community development. In R. Phillips \& R. H. Pittman (Eds.), An introduction to community development (pp. 3-19). Routledge.

Pigg, K., Gasteyer, S. P., Martin, K. E., Keating, K., \& Apaliyah, G. P. (2013). The community capitals framework: An empirical examination of internal relationships. Community Development, 44(4), 492-502.

Rogers, M., \& Ryan, R. (2001). The triple bottom line for sustainable community development. Local Environment, 6(3), 279-289.

Roman, J. \& Ricketts, T. (2020, August 7). Twitter posts show that people are profoundly sad - and visiting parks to feel happy. EcoWatch. Retrieved 17 August 2020 from https://www.ecowatch.com/ parks-mental-health-2646918250.html?rebelltitem=2\#rebelltitem2.

Romano, A. (2020, March 12). Stuck at home? These 12 famous museums offer virtual tours you can take on your couch. Travel + Leisure. https://www.travelandleisure.com/attractions/museums-galleries/ museums-with-virtual-tours. Accessed 29 Nov 2021.

Sandifer, P., Sutton-Grier, A., \& Ward, B. (2015). Exploring connections among nature, biodiversity, ecosystem services, and human health and well-being: Opportunities to enhance health and biodiversity conservation. Ecosystem Services, 12, 1-15.

Satin, H. (2020, March 20). The environment bill - Mandatory biodiversity net gain. Farrer \& Co. Retrieved 16 November 2020 from https:/www.farrer.co.uk/news-and-insights/the-environmentbill\%2D\%2Dmandatory-biodiversity-net-gain/.

Schuster, R., Germain, R. R., Bennett, J. R., Reo, N. J., \& Arcese, P. (2019). Vertebrate biodiversity on indigenous-managed lands in Australia, Brazil, and Canada equals that in protected areas. Environmental Science \& Policy, 101, 1-6.

Sommer, L. (2020, August 24). To manage wildfire, California looks to what tribes have known all along. National Public Radio. Retrieved 17 November 2020 from https://www.npr.org/2020/08/24/89942 2710/to-manage-wildfire-california-looks-to-what-tribes-have-known-all-along.

Stanley, T. (2020, October 11). Jewish Federation of Tulsa to host virtual lecture series on antisemitism. Tulsa World. https://tulsaworld.com/news/local/jewish-federation-of-tulsa-to-host-virtual-lecture-serieson-antisemitism/article_57d1cc82-080b-11eb-b540-c329da579cea.html. Accessed 29 Nov 2021.

Talmage, C. A., \& Gassert, T. A. (2020). Unsettling entrepreneurship by teaching dark side theories. Entrepreneurship Education and Pedagogy, 3(3), 316-345. https://doi.org/10.1177/2515127420 910415

Talmage, C. A., Lewis, R., Flowers, K., \& Cleckner, L. (2020). Community innovation and small liberal arts colleges: Lessons learned from local partnerships and sustainable community development. In R. Philips, E. Trevan, \& P. Krager (Eds.), Research handbook on community development (pp. 416-438). Edward Elgar Publishing.

Theodori, G. L. (2005). Community and community development in resource-based areas: Operational definitions rooted in an interactional perspective. Society and Natural Resources, 18(7), 661-669.

Thoumi, G. \& Waugh, J. (2018, July 28). We need a green life support plan (article). Mongabay. Retrieved 17 August 2020 from https://news.mongabay.com/2020/07/we-need-a-green-life-suppo rt-plan-article/.

Throsby, D. (1999). Cultural capital. Journal of Cultural Economics, 23, 3-12. https://doi.org/10.1023/A: 1007543313370

Trevan, E. S. (2016). The influence of import substitution on community development as measured by economic wealth and quality of life (doctoral dissertation, Arizona State University).

Tripp, B. (2019, October 29). What western states can learn from native American wildfire management strategies. The Conversation. Retrieved 17 November 2020 from https://theconversation.com/whatwestern-states-can-learn-from-native-american-wildfire-management-strategies-120731.

Tsosie, R. (2020). The legal and policy dimensions of Indigenous Data Sovereignty (IDS). In M. Walter, T. Kukutai, S. R. Carroll, \& D. Rodriguez-Lonebear (Eds.), Indigenous data sovereignty and policy (pp. 204-225). Routledge.

van Dorn, A., Cooney, R. E., \& Sabin, M. L. (2020). COVID-19 exacerbating inequalities in the US. Lancet, 395(10232), 1243. 
Walker, A. (2020, Jan 15). Farmers to be paid for boosting wildlife and tackling climate change under new law. ITV. Retrieved 26 August 2020 from https://www.itv.com/news/2020-01-16/new-laws-toreward-farmers-for-boosting-wildlife-and-tackling-climate-change.

Watson, R. (2020). Take a virtual visit to a national park. National Park Foundation. https://www. nationalparks.org/connect/blog/take-virtual-visit-national-park?gclid=CjwKCAjww5r8BRB 6EiwArcckC4slzVIi-eqpRMW9eJIT2nW0YZyq91wj3aSV9F9inSnnI5xrlqEV1xoCeJMQAvD_ BwE. Accessed 29 Nov 2021.

Western, D., Russell, S., \& Cuthill, I. (2009). The status of wildlife in protected areas compared to nonprotected areas of Kenya. PLoS One, 4(7), e6140.

Wildlife Conservation Research Unit (WildCru). (n.d.). Research - Farming and wildlife. Retrieved 22 November 2020 from https://www.wildcru.org/research/theme/farming-and-wildlife/.

Wiseman, J., \& Brasher, K. (2008). Community wellbeing in an unwell world: Trends, challenges, and possibilities. Journal of Public Health Policy, 29, 353-366. https://doi.org/10.1057/jphp.2008.16

Zaferatos, N. C. (2015). Planning the American Indian reservation: From theory to empowerment. Syracuse University Press.

Zou, T., Su, Y., \& Wang, Y. (2018). Examining relationships between social capital, emotion experience and life satisfaction for sustainable community. Sustainability, 10(8), 2651.

Publisher's Note Springer Nature remains neutral with regard to jurisdictional claims in published maps and institutional affiliations.

\section{Authors and Affiliations}

\section{Craig A Talmage ${ }^{1}\left(\mathbb{D} \cdot\right.$ Beth Allgood $^{2} \cdot$ Brien K. Ashdown $^{3} \cdot$ Ava Brennan $^{1}$. Sally Hill ${ }^{4}$ Eric Trevan ${ }^{5}$. John Waugh ${ }^{6}$}

Beth Allgood

allgood@onenatureglobal.org

Brien K. Ashdown

Ashdown@hws.edu

Ava Brennan

Ava.Brennan@HWS.edu

Sally Hill

sallyhill@talk21.com

Eric Trevan

etrevan@hotmail.com

John Waugh

waugh2k@gmail.com

1 Entrepreneurial Studies, Hobart \& William Smith Colleges, 300 Pulteney Street, Geneva, NY 14456, USA

2 One Nature, Riverdale Park, MD, USA

3 Department of International Studies, American University of Sharjah, Sharjah, United Arab Emirates

4 Community Health International (CHI) Limited, Wellington, Somerset, UK

5 The Evergreen State College, Olympia, Washington, USA

6 Independent Advisor, Delaplane, VA, USA 